\title{
Mental health and criminality: A Sri Lankan perspective
}

\author{
Rajiv Weerasundera
}

\section{Summary}

Recent mass killings in the United States by a perpetrator apparently having a mental disorder have led to questions about the efficiency of mental health services in that country. Sri Lanka has yet to encounter such mental health related catastrophes. However a less than comprehensive provision of specialised services in Child Psychiatry and Forensic Psychiatry, a lack of a formal community mental health care network and the ready availability of weapons which are a residue of years of armed conflict suggests that its potential for such an event remains high.

SL J Psychiatry 2012; 3 (2):1-2
The recent massacre of school children in the United States by a person supposedly suffering from a mental disorder has refocused global attention not only on criminal behavior among the mentally ill but also on the significance of identifying and treating mental illness and the often tragic consequences of failing to do so.

The association between mental illness and criminality is well established. The risk of a mentally ill person engaging in a criminal act is significantly greater than that of the general population and this is a finding replicated in many studies $(1$, 2). Conversely, the incidence of mental illness is also higher in prison populations, compared to the general population (3). However, it also worthwhile noting that all senseless killings are not the result of mental illness: the offender in the July 2011 massacre of seventy seven people in Norway was found not to suffer from a mental disorder (4).

Mental illness carries with it a stigma that is quite separate from the stigma of the illness itself. The mentally ill may be perceived as 'dangerous', a factor that alienates them even more from social interaction. This sets up a vicious cycle that discourages treatment seeking and aggravates any preexisting disorder.

Historically, mental health related legislation has often been a sequel to a mental health related catastrophe rather than the former being utilised to prevent the latter. The Mc Naughton rules which form the basis of mental health legislation in many countries were the result of an unsuccessful bid to assassinate a British Prime Minister by a person suffering from Schizophrenia (5). More recently, gun control laws in the United States (the 'Brady Act') followed an attempt to assassinate an American President by a person suffering from an erotomanic delusional disorder (6).

While the recent massacre in the United States has also led to calls for tighter gun control legislation in that country, it has succeeded in shedding light on another, less debated, aspect of mental illness. That is because the alleged offender who is thought to be mentally ill was apparently not under any formal care for his disorder. This was despite his behaviour being observed by many to deviate from the normal from a very young age and while living in a country which boasts of one of the more advanced health care systems in the world, catering to some of the most specialized services in Psychiatry.
The United States has an estimated 13 million people with a serious mental disorder, most of them cared for by the government or other state sponsored institutions (7). Questions are now being raised as to how the offender in the incident in the United States 'escaped' from being 'captured by the system'.

It has been demonstrated that mass killings, though by no means common, are not isolated incidents. Its perpetrators have identifiable characteristics such as being bullied as children, social isolation, obsessive traits and grandiosity (8). It is of course easier to recognize these markers in retrospect but arguably, each of these characteristics also has the potential to present to a mental health care system.

Considering the prevalence of schizophrenia to have little variability globally and be about 0.46 per cent, it could be estimated that Sri Lanka is home to nearly 100,000 sufferers of the disease, the illness most likely to lead to serious crime (9). Of more significance is the fact that resources for the delivery of mental health care in Sri Lanka are stretched thin. Sufferers from mental health problems are usually brought to the attention of services by families or when their disorders lead to behaviours that lead to public complaints or attract intervention by law enforcement authorities. As such, there is no 'system' in place for the identification of the mentally ill or to initiate treatment for them.

The Sri Lankan scenario is also rife with other risk factors: specialized services in Child Psychiatry and Forensic Psychiatry are scarce and the country does not have a formal community health network that encompasses the island to monitor the wellbeing of those with more serious mental disorders. It also recovering from a series of armed conflicts that has resulted in a 'gun culture' that increases the availability of weapons.

This would suggest that Sri Lanka the country is at an elevated risk of mental health related violence. Fortunately, the country has not witnessed senseless mass killings by perpetrators with mental illness, its experiences in this respect being confined to politically motivated killings during the years of civil unrest.

This may be because culturally, any form of killing is frowned upon in the country. It may also be hypothesized that this is 
because closer knit family units are often able to compensate for deficiencies in the mental health care delivery system, assertively and at times arbitrarily bringing those in need of care to the attention of service providers and also offering psychological support within an extended family unit to those in need, both being factors which do not operate optimally in western-oriented societies.

That is not to say that the mentally ill in Sri Lanka are not culpable. Individual acts of serious violence by the mentally ill are regularly encountered in clinical practice. They have been dealt with by the criminal justice system in the country which makes allowances for mental disorder in disposing of offenders. However, the laws concerned are archaic, dating back more than a century and, as a result, the method of disposal is geared more towards shielding society from the mentally ill rather than being therapeutic (10).

In recent years, there has also been a marked escalation of crime in Sri Lanka. The reasons for this are as yet unclear but some of these acts border on the senseless. A disturbing feature is that they have received widespread media coverage which has included glaring publicity for the accused-a factor known to attract potential perpetrators.

Sri Lanka may have been fortunate in not experiencing mass scale violence committed by the mentally ill. However, that is no reason to be complacent. In an overburdened mental healthcare delivery system, the paucity of mental health related criminality has been a blessing. Yet, with influences from the rest of the world filtering through to the country through instant global communication, it would only be prudent to be prepared.

\section{Declaration of interest}

None

\section{Rajiv Weerasundera,}

Senior Lecturer, Department of Psychiatry,

Faculty of Medical Sciences,

University of Sri Jayawardenepura, Sri Lanka

E mail: rajivweerasundera@yahoo.com

\section{References}

1. Hodgins S. Mental disorder, intellectual deficiency, and crime. Evidence from a birth cohort. Arch Gen Psychiatry. 1992;49:476-483. CrossRef

2. Walsh E, Buchanan A. Fahy T. Violence and schizophrenia: examining the evidence. Br J Psychiatry.2002;180:490-495. CrossRef

3. Fazel S, Danesh J. Serious mental disorder in 23000 prisoners: a systematic review of 62 surveys. Lancet. 2002;359:545-550. CrossRef

4. Nau JY. Psychiatry in the eyes of Anders Behring Breivik. Rev Med Suisse. 2012; 8(340):1030-1.CrossRef

5. Bennett AOM. Criminal law as it pertains to "mentally incompetent defendants': a McNaughton rule in the light of cognitive neuroscience. Aust N Z J Psychiatry. 2009; 43(4):289-99. CrossRef

6. Price M, Norris DM. National Instant Criminal Background Check Improvement Act: Implications for persons with mental illness. J Am Acad Psychiatry and the Law. 2008; 36(1):123-130.

7. Kessler RC, Chiu WT, Demler O, Merikangas KR, Walters EE. Prevalence, severity, and comorbidity of 12-month DSM-IV disorders in the National Comorbidity Survey Replication. Arch Gen Psychiatry. 2005 Jun; 62(6):617-27. CrossRef

8. Mullen P. The autogenic (self-generated) massacre. Beh Sci Law. 2004;22:311-323 CrossRef

9. Saha S, Chant D, Welham J, McGrath J. A systematic review of the prevalence of schizophrenia.PLoS Med. 2005;2:e141. CrossRef

10. Weerasundera R. Mental health legislation in Sri Lanka: the time for change is now. Sri Lanka J of Psychiatry. 2011; 2 (2):43-44. 